\title{
Multimodal imaging of aberrant macular microvessel crossing the foveal avascular zone in two young adults
}

\author{
Xianming Jiang ${ }^{*}$, Cong Zheng, Fangfang Du and Shibei Ai
}

\begin{abstract}
Background: The traditional view is that there are no vessels in the foveal avascular zone. The two cases we report show microvessels crossing the foveal avascular zone.

Case presentation: A man and a woman, both 25 years old, were both incidentally found on optical coherence tomography angiography (OCTA) to have unilateral aberrant microvessels crossing the foveal avascular zone in their left eyes. Visual acuity was preserved in both patients. The vessel density (VD) and perfusion density (PD) of the eyes with the aberrant microvessels were all higher than those of the contralateral eyes. Nevertheless, measurements of foveal avascular zone (FAZ) dimensions, including its area, perimeter and circularity, were smaller in the left eyes than in the right eyes. No complications were recorded.

Conclusions: To date, aberrant microvessels crossing the foveal avascular zone have not been found to impair visual function. OCTA is a non-invasive and quick method that does not require dilation or the use of fluorescein dye. It is a reliable tool for the detection of aberrant microvessels crossing the foveal avascular zone.
\end{abstract}

Keywords: Foveal avascular zone, Aberrant microvessel, Optical coherence tomography angiography, Congenital retinal macrovessel

\section{Background}

The fovea is the centre of the macula and is characterized by thinning of the outer nuclear layer. In the foveola, the most central portion of the fovea, the photoreceptors are all cones. The fovea is supplied entirely by the choriocapillaris. The fovea corresponds to the retinal avascular zone viewed on fluorescein angiography [1]. By definition, there are no vessels in the foveal avascular zone. OCTA produces more detailed, higher resolution images of the vasculature than are obtained using conventional dye angiography [2] and is a convenient method for the noninvasive

\footnotetext{
* Correspondence: jiangxm26@mail.sysu.edu.cn
Department of Ophthalmology, The Seventh Affiliated Hospital of Sun

*Correspondence: jiangxm26@mail.sysu.edu.cn
Department of Ophthalmology, The Seventh Affiliated Hospital of Sun Yat-sen University, 628 Zhenyuan Road, Guangming District, Shenzhen 518000, P.R. China
}

study of the foveal avascular zone. We present two unrelated cases in which unilateral aberrant microvessels crossing the foveal avascular zone were coincidentally detected using OCTA. While there have been many case reports of aberrant macular vessels, there is no clear indication as to whether the aberrant microvessels found in these cases passed through the foveal avascular zone.Both patients were examined at the Department of Ophthalmology of the Seventh Affiliated Hospital Sun Yat-sen University in Shenzhen, China. During routine health checks, on OCTA, a man and woman, both 25 years old, were incidentally found to have unilateral aberrant microvessels crossing the foveal avascular zone in the left eye. We then performed ophthalmological examinations, including optometry, measurement of intraocular pressure with a non-contact tonometer, anterior

(C) The Author(s). 2020 Open Access This article is licensed under a Creative Commons Attribution 4.0 International License, which permits use, sharing, adaptation, distribution and reproduction in any medium or format, as long as you give appropriate credit to the original author(s) and the source, provide a link to the Creative Commons licence, and indicate if changes were made. The images or other third party material in this article are included in the article's Creative Commons licence, unless indicated otherwise in a credit line to the material. If material is not included in the article's Creative Commons licence and your intended use is not permitted by statutory regulation or exceeds the permitted use, you will need to obtain permission directly from the copyright holder. To view a copy of this licence, visit http://creativecommons.org/licenses/by/4.0/ The Creative Commons Public Domain Dedication waiver (http://creativecommons.org/publicdomain/zero/1.0/) applies to the data made available in this article, unless otherwise stated in a credit line to the data. 


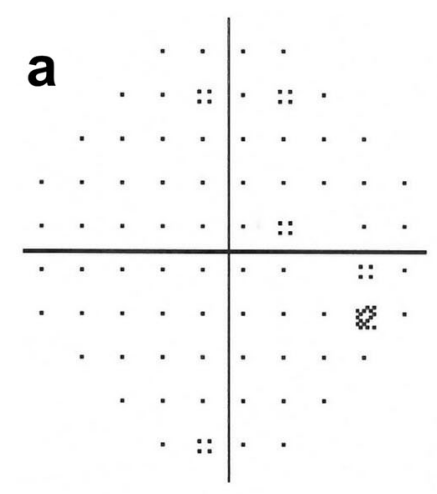

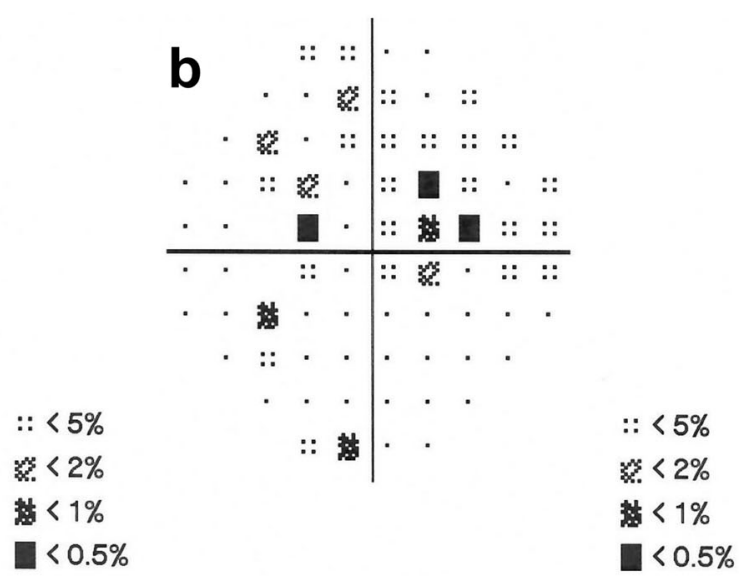

Fig. 1 Visual fields (central 30-2 threshold test) in patient 1. a Examination of the visual field showing it was normal in the right eye; $\mathbf{b}$ Examination of the visual field showing a few paracentral scotomas in the left eye

segment examination, visual field examination (Zeiss, 750i), colour fundus photography (Zeiss, VISUCAM224) and OCTA (Zeiss, Cirrus HD 5000) in both patients.

\section{Case presentations \\ Patient 1}

The first patient was a 25 -year-old man with moderate myopia. On ophthalmic examination, his best-corrected visual acuity was $20 / 20$ in both eyes, and the intraocular pressure was within normal limits. The anterior segment examinations performed in both eyes were normal. There were paracentral scotomas in his left eye, and a glaucoma hemifield test (GHT) of the left eye was borderline compared with the GHT of the normal right eye (Fig. 1). It was not easy to find the aberrant microvessel that crossed the foveal avascular zone using colour fundus photography (Fig. 2); however, a fundus image on OCTA clearly revealed the vessel in the left eye (Fig. 3). This aberrant vessel was a small perifoveolar arteriovenous communication. The central retinal artery divides into two branches at the optic disc: the superior artery and the inferior artery. After an extremely short ascending course following its origin, the superior artery separated into a macular branch that then horizontally reached the macula. The abnormal vessel traversed vertically over the entire macula and eventually converged with the branch of the inferior temporal vein. For the central or inner ring, the values for VD and PD obtained in the left eye surpassed those of the opposite eye (Fig. 4, Table 1). Nevertheless, the measurements obtained for FAZ dimensions, including its area, perimeter and circularity, were markedly smaller in the left eye than in the contralateral eye (Table 2). Macular oedema and exudation were not recorded (Fig. 5).

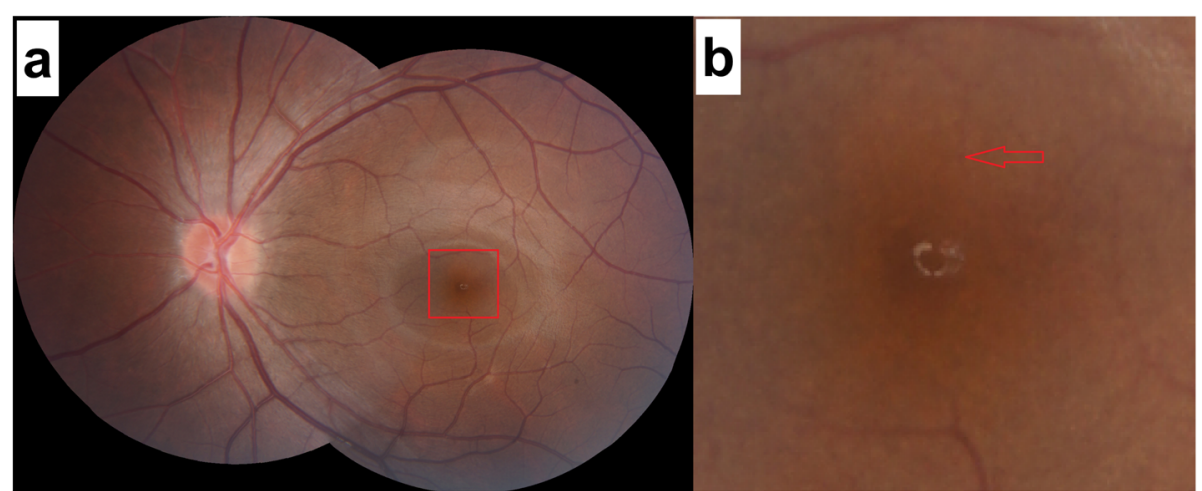

Fig. 2 Colour fundus photos of the left eye in patient 1. a 45-degree 2-direction fundus photograph. The red frame indicates the position of the amplifier section; $\mathbf{b}$ Amplifier section. The red arrow shows the location of the aberrant microvessel that crossed the foveal avascular zone 


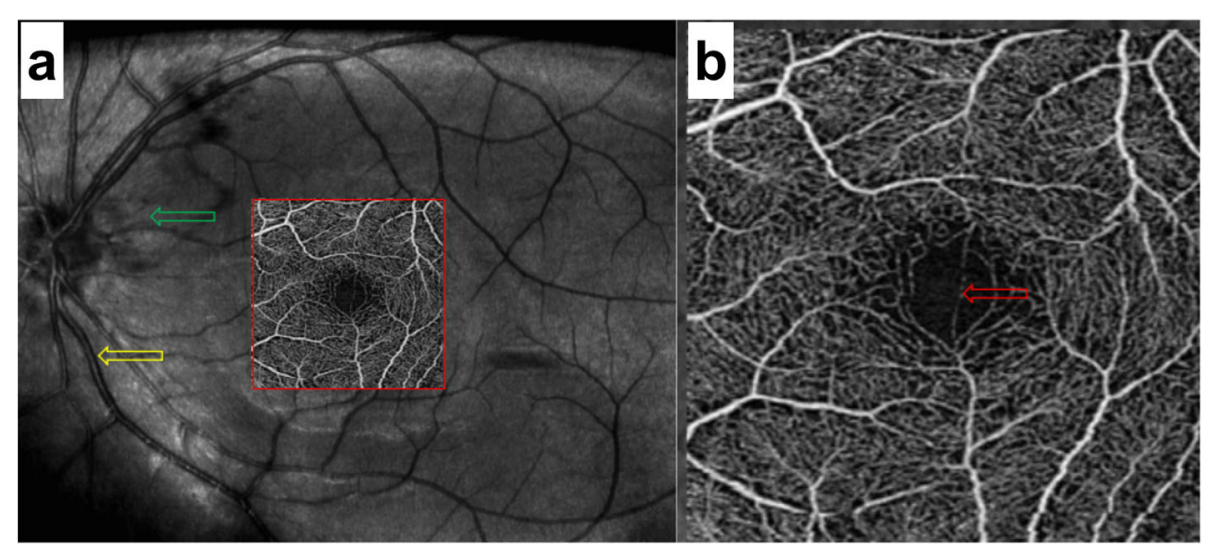

Fig. 3 Fundus images of the left eye on OCTA ( $3 \mathrm{~mm} \times 3 \mathrm{~mm}$ scan pattern) in patient 1. a The red frame indicates the amplifier section, the green frame indicates the original artery, and the yellow frame indicates the confluent vein. $\mathbf{b}$ The red arrow reveals the location of the aberrant microvessel that crossed the foveal avascular zone

\section{Patient 2}

The second patient was a 25-year-old woman with no past ophthalmic history. Visual acuity was $20 / 20$ without correction in both eyes. Intraocular pressure measurement, anterior segment examination and visual field were normal in both eyes. A fundus image was normal in the right eye, whereas in the left eye, it revealed the presence of an abnormal vessel (Fig. 6). This aberrant microvessel was a communication of the superior temporal artery and the inferior temporal vein. The VD and PD values obtained in the left eye exceeded those obtained in the other eye (Fig. 7, Table 3), whereas the measurements of FAZ dimensions were smaller in the left eye than in the right eye (Table 4 ). No ocular complications occurred.

\section{Discussion and conclusions}

Many aberrant macular vessels have been reported in the past. Congenital retinal macrovessel is one of the most frequently reported events and was first described in 1869 by Mauthner [3] and named in 1982 by Brown. It refers to one large vessel, most often a vein, that traverses through the central macula and crosses the horizontal raphe [4]. Congenital retinal macrovessel is rare and tends to remain stable. As shown in a five-year follow-up study by K. Petropoulos et al., these anomalous vessels are derived from branches of retinal arteries or veins [5]. Because the majority of sufferers are asymptomatic, congenital retinal macrovessel is usually discovered unexpectedly on physical examinations or in patients with other ophthalmic diseases. In many studies and in normal eyes [6], partial congenital retinal macrovessel can be accompanied by branch retinal artery occlusion [7], retinal deep capillary ischaemia [8], macular retinal cavernous haemangioma [9], retinal arteriolar macroaneurysm [10, 11], retinal peripheral telangiectasia [12], vitreous haemorrhage [13], retinal detachment [14], and even venous malformations of the brain [15]. Archer suggested that retinal arteriovenous communications could be divided into three groups [16]. Congenital retinal macrovessel was part of Group 1, which presents as interposition of an arteriolar or abnormal capillary plexus between the major communicating vessels [16].

Aberrant macular vessels have been reported in the past that present as one large vessel that traverses through the central macula. However, it is not clear whether they cross the FAZ. In contrast to previous reports, the two cases we reported involved microvessels that crossed the foveal avascular zone. We can therefore call them "foveal avascular zone aberrant microvessels" (FAZAMs).

In the past, the detection of aberrant macular vessels depended on fluorescein angiography or colour fundus photography. These examinations require the dilation of the pupils, causing blurred vision. Fluorescein angiography is invasive and a lengthy examination occasionally accompanied with allergic reactions. All of these inconveniences impact screening and follow-up.

Currently, noninvasive and rapid OCTA facilitates examinations. OCTA does not require dilation or fluorescein dye [17] and thus avoids drug-related contraindications. Not only is OCTA accessible for visualization of the retinal vasculature and FAZ, but it also has favourable repeatability and reproducibility $[18,19]$. 


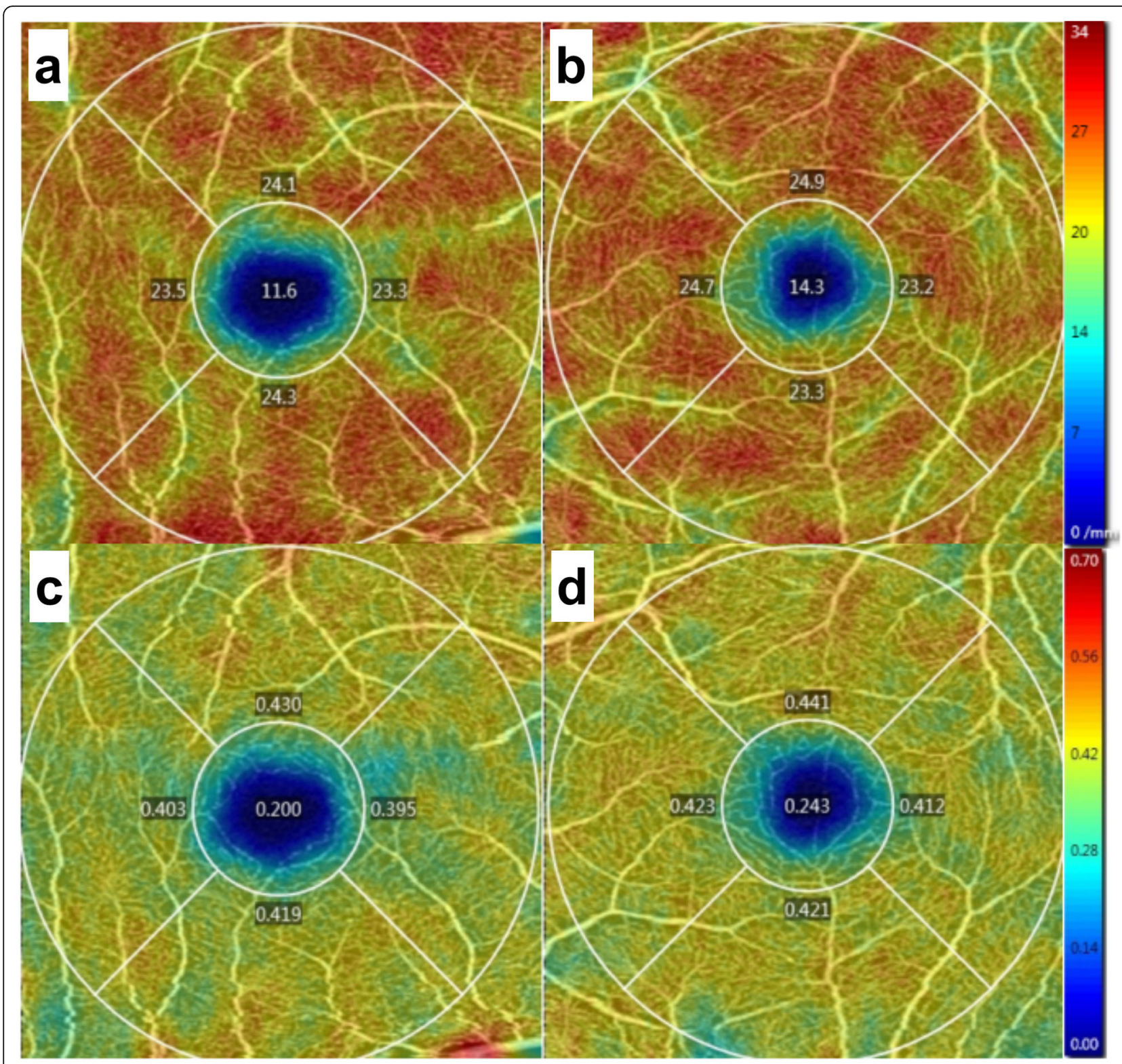

Fig. 4 Vessel density and perfusion density on OCTA ( $3 \mathrm{~mm} \times 3 \mathrm{~mm}$ scan pattern) in patient 1. a Vessel density of the right eye; $\mathbf{b}$ Vessel density of the left eye; c Perfusion density of the right eye; $\mathbf{d}$ Perfusion density of the left eye

Table 1 Vessel density and perfusion density by OCTA in patient 1 ( $3 \mathrm{~mm} \times 3 \mathrm{~mm}$ scan pattern)

\begin{tabular}{llllllll}
\hline Parameter & Right Eye & & & \multicolumn{2}{l}{ Left Eye } & \\
\cline { 2 - 4 } & Central & Inner & Full & & Central & Inner & Full \\
\hline Vessel Density $\left(\mathrm{mm}^{-1}\right)$ & 11.6 & 23.8 & 22.4 & 14.3 & 24.0 & 22.9 \\
Perfusion Density & 0.200 & 0.412 & 0.388 & 0.243 & 0.424 & 0.404 \\
\hline
\end{tabular}

Table 2 Foveal avascular zone by OCTA in patient 1 ( $3 \mathrm{~mm} \times 3 \mathrm{~mm}$ scan pattern)

\begin{tabular}{|c|c|c|c|c|c|c|}
\hline \multirow[t]{2}{*}{ Parameter } & \multicolumn{3}{|l|}{ Right Eye } & \multicolumn{3}{|l|}{ Left Eye } \\
\hline & Area $\left(\mathrm{mm}^{2}\right)$ & Perimeter $(\mathrm{mm})$ & Circularity & Area $\left(\mathrm{mm}^{2}\right)$ & Perimeter (mm) & Circularity \\
\hline$\overline{F A Z}$ & 0.25 & 2.13 & 0.69 & 0.18 & 1.97 & 0.57 \\
\hline
\end{tabular}




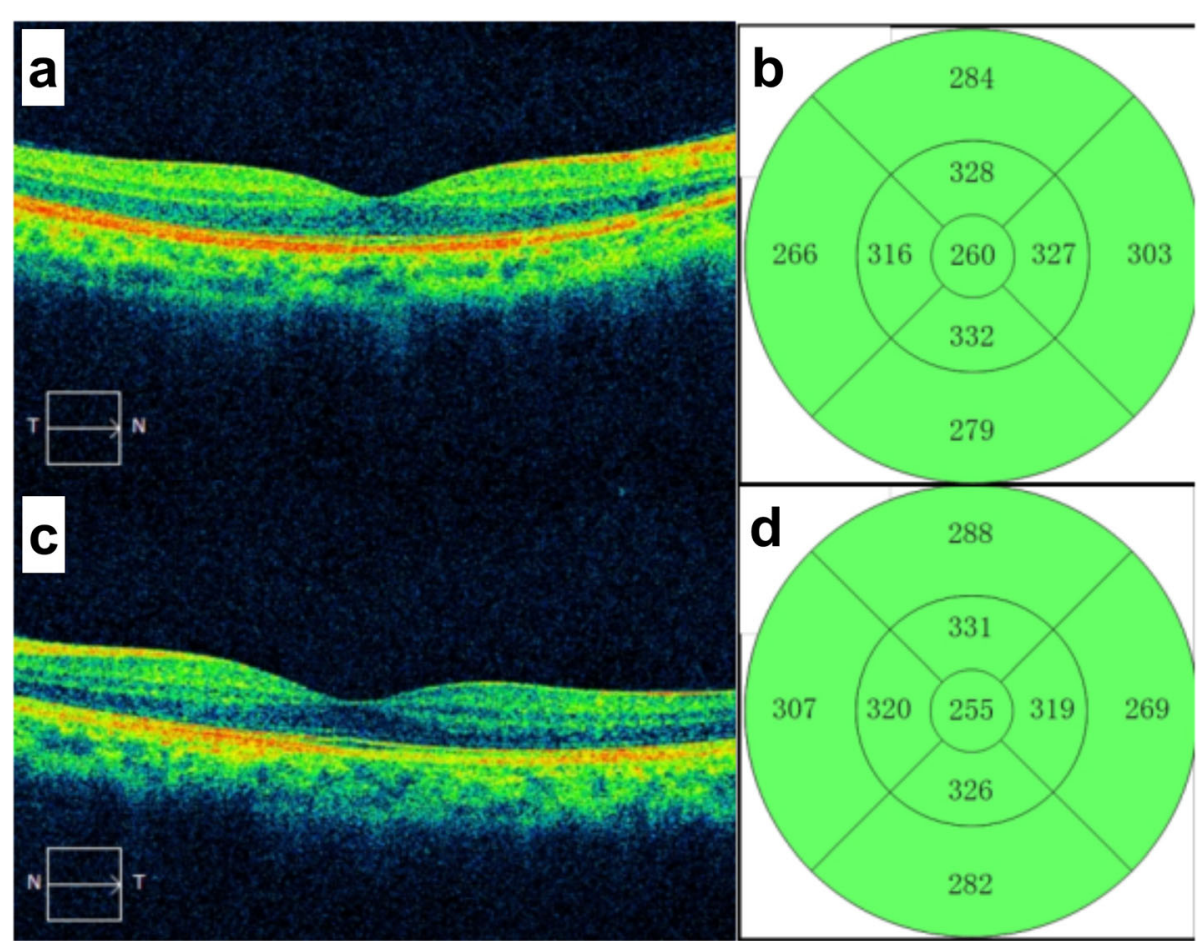

Fig. 5 Macular thickness on OCT $(512 \times 128$ scan pattern) in patient 1. a Horizontal scan of the right eye; b Inner limiting membraneretinal pigment epithelium (ILM-RPE) thickness of the right eye; $\mathbf{c}$ Horizontal scan of the left eye; (d) ILM-RPE thickness of the left eye

In this study, OCTA revealed the origin and location of aberrant microvessels that crossed the foveal avascular zone and allowed the digitalization and visualization of the vessel density and perfusion density of the retina and measurements of foveal avascular zone dimensions and the macular thickness that excluded the ocular complications involving macular oedema and exudation. Our description of aberrant microvessels crossing the foveal avascular zone was comprehensive and systematic. Most importantly, the VD and PD were higher in the eyes with aberrant microvessels crossing the foveal avascular zone than in those the contralateral eyes, whereas the measurements of FAZ dimensions were lower. This was probably because the arteriovenous anastomosis above the

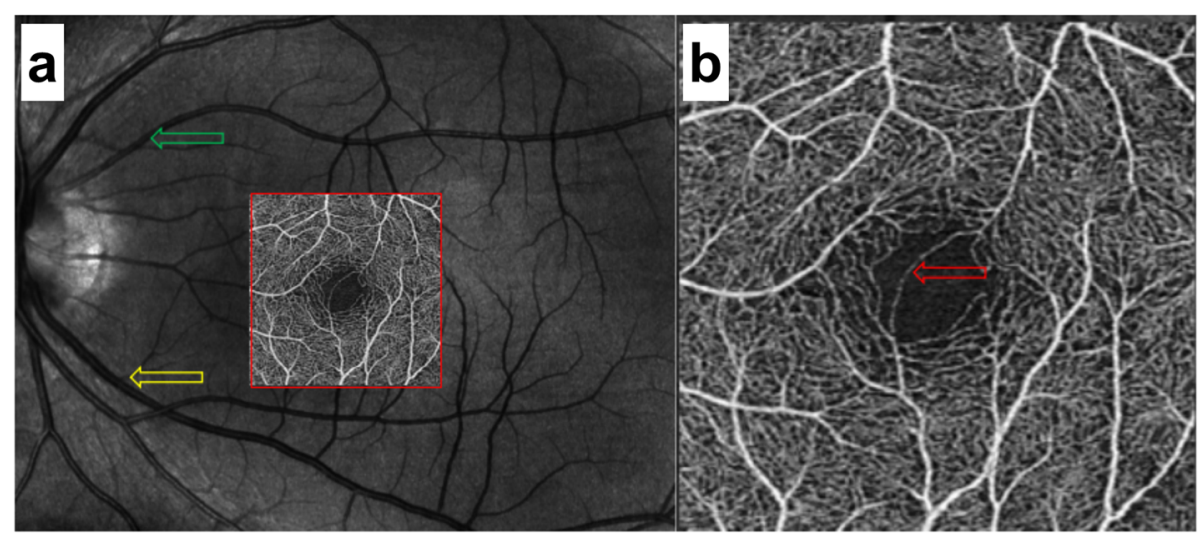

Fig. 6 Fundus images of the left eye on OCTA ( $3 \mathrm{~mm} \times 3 \mathrm{~mm}$ scan pattern) in patient 2. a The red frame indicates the amplifier section, the green frame indicates the original artery, and the yellow frame indicates the confluent vein. $\mathbf{b}$ The red arrow reveals the location of the aberrant microvessel that crossed the foveal avascular zone 


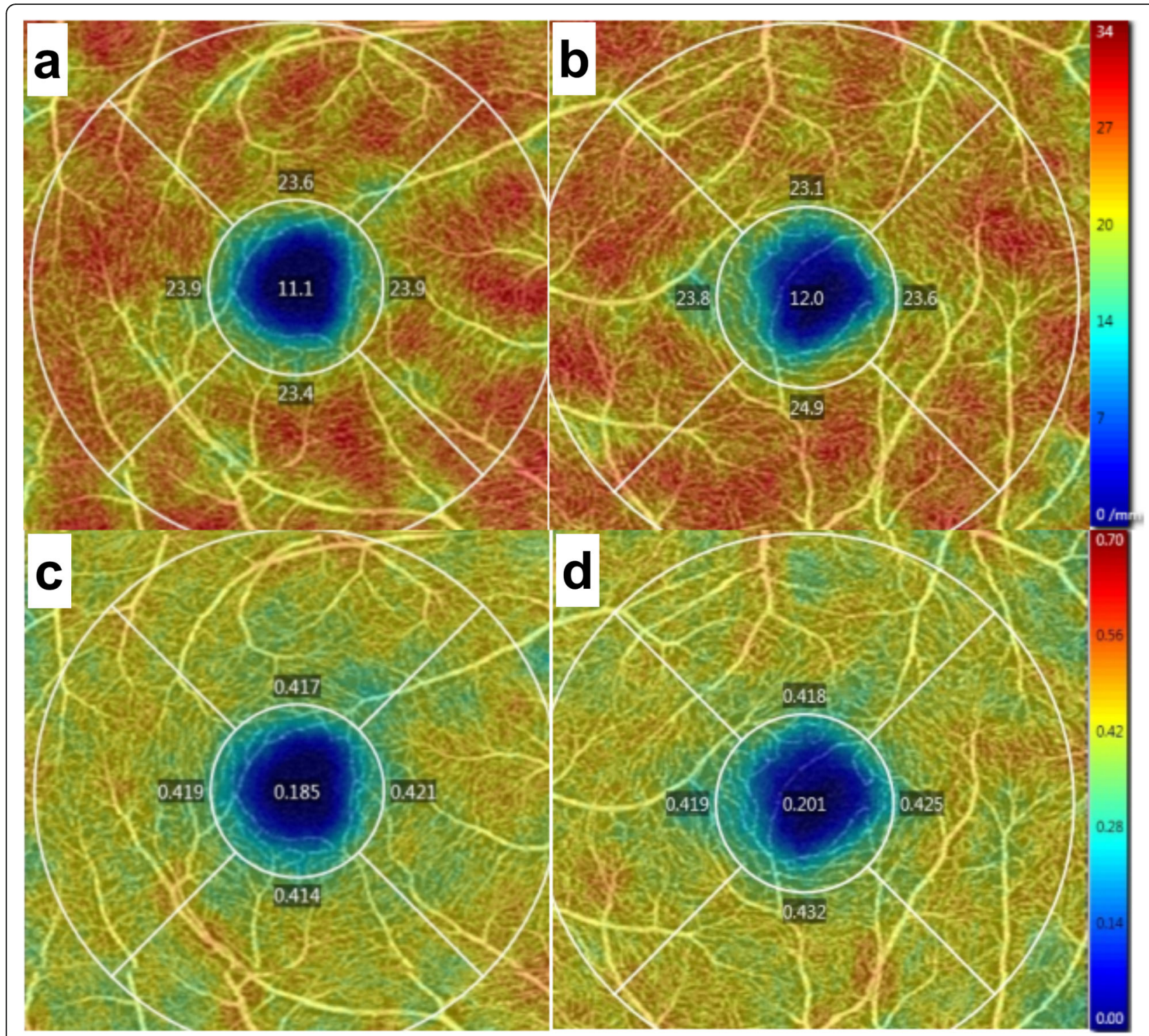

Fig. 7 Vessel density and perfusion density on OCTA ( $3 \mathrm{~mm} \times 3 \mathrm{~mm}$ scan pattern) in patient 2. a Vessel density of the right eye; $\mathbf{b}$ Vessel density of the left eye; $\mathbf{c}$ Perfusion density of the right eye; $\mathbf{d}$ Perfusion density of the left eye

macular area increased the arterial supply of the retina and damaged the circular configuration of the FAZ. More clinical data need to be acquired to support this opinion.

We show that foveal avascular zone aberrant microvessels can cross the FAZ; however, their

Table 3 Vessel density and perfusion density by OCTA in patient 2 ( $3 \mathrm{~mm} \times 3 \mathrm{~mm}$ scan pattern)

\begin{tabular}{lllllllll}
\hline Parameter & \multicolumn{3}{l}{ Right Eye } & & & Left Eye & & \\
\cline { 2 - 4 } & Central & Inner & Full & & Central & Inner & Full \\
\hline Vessel Density $\left(\mathrm{mm}^{-1}\right)$ & 11.1 & 23.7 & 22.3 & & 12.0 & 23.8 & 22.5 \\
Perfusion Density & 0.185 & 0.418 & 0.392 & & 0.201 & 0.424 & 0.399 \\
\hline
\end{tabular}

visual function was not affected. The possible reasons are as follows: the diameter of the aberrant microvessel is too small to affect visual function, or the vision changes caused by the abnormal blood vessels were too small to be detected by existing instruments. Aberrant blood vessels are congenital, and functional compensation may occur during macular development. Of course, conclusions regarding the follow-up effects of visual function require further observation.

In conclusion, aberrant microvessels were found in the foveal avascular zone, which should not contain vessels; however, no visual function impairment was found. OCTA is noninvasive and rapid, does not 
Table 4 Foveal avascular zone by OCTA in patient 2 ( $3 \mathrm{~mm} \times 3 \mathrm{~mm}$ scan pattern)

\begin{tabular}{|c|c|c|c|c|c|c|}
\hline \multirow[t]{2}{*}{ Parameter } & \multicolumn{3}{|l|}{ Right Eye } & \multicolumn{3}{|l|}{ Left Eye } \\
\hline & Area $\left(\mathrm{mm}^{2}\right)$ & Perimeter (mm) & Circularity & Area $\left(\mathrm{mm}^{2}\right)$ & Perimeter (mm) & Circularity \\
\hline FAZ & 0.29 & 2.14 & 0.79 & 0.20 & 2.01 & 0.61 \\
\hline
\end{tabular}

require dilation or fluorescein dye, and is a reliable tool to observe aberrant microvessels crossing the foveal avascular zone.

\section{Abbreviations}

OCTA: Optical coherence tomography angiography; VD: Vessel density; PD: Perfusion density; FAZ: Foveal avascular zone; GHT: Glaucoma hemifield test; ILM-RPE: Inner limiting membrane- retinal pigment epithelium

\section{Acknowledgements}

Not applicable.

\section{Authors' contributions}

JX was responsible for writing manuscript, revising manuscript and making figures. ZC was responsible for making tables and writing technical part of manuscript. DF and AS were responsible for examining the patient and analyzing data. All four writers had given final approval of the version to be published and agreed to be accountable for all aspects of the work in ensuring that questions related to the accuracy or integrity of any part of the work are appropriately investigated and resolved.

\section{Funding}

The authors declare no funding was received for this project.

\section{Availability of data and materials}

The datasets used and analysed during the current study are available from the corresponding author on a reasonable request.

\section{Ethics approval and consent to participate}

Not applicable.

\section{Consent for publication}

Participants gave written consent to have anonymous data used for publication in this case report.

\section{Competing interests}

The authors declare that they have no competing interests.

Received: 26 November 2019 Accepted: 8 May 2020

Published online: 25 May 2020

\section{References}

1. Riordan-Eva P. Chapter 1. Anatomy \& Embryology of the eye. In: Riordan-Eva $P$, Cunningham ET, editors. Vaughan \& Asbury's general ophthalmology. 18th ed. New York: The McGraw-Hill Companies; 2011.

2. Tan ACS, Tan GS, Denniston AK, Keane PA, Ang M, Milea D, et al. An overview of the clinical applications of optical coherence tomography angiography. Eye (Lond). 2018;32(2):262-86.

3. Mauthner L. Lehrbuch der Ophthalmoscopie. Vienna: Tendler \& Co; 1869.

4. GC KB, Donoso LA, Magargal LE, Goldberg RE, Sarin LK. Congenital retinal macrovessels. Arch Ophthalmol. 1982;100:1430-6.

5. Petropoulos IK, Petkou D, Theoulakis PE, Kordelou A, Pournaras CJ, Katsimpris JM. Congenital retinal macrovessels: description of three cases and review of the literature. Klin Monatsbl Augenheilkd. 2008;225:469-72.

6. Strampe MR, Wirostko WJ, Carroll J. A case of congenital retinal macrovessel in an otherwise normal eye. Am J Ophthalmol Case Rep. 2017:8:18-21.

7. Goel N, Kumar V, Seth A, Ghosh B. Branch retinal artery occlusion associated with congenital retinal macrovessel. Oman J Ophthalmol. 2014;7:96-7.

8. Hasegawa T, Ogata N. Retinal deep capillary ischemia associated with an occluded congenital retinal macrovessel. Retin Cases Brief Rep. 2017;11:27780.
9. Thanos A, Randhawa S, Drenser KA. Macular retinal cavernous hemangioma associated with congenital retinal macrovessel. JAMA Ophthalmol. 2016;134: e161683.

10. Goel N, Kumar V, Seth A, Ghosh B. Intravitreal bevacizumab in congenital retinal macrovessel with retinal arteriolar macroaneurysm. Saudi J Ophthalmol. 2015;29:292-4.

11. Sebrow DB, Cunha de Souza E, Belúcio Neto J, Roizenblatt M, Zett Lobos C, Paulo Bonomo P, et al. Macroaneurysms associated with congenital retinal macrovessels. Retin Cases Brief Rep. 2017;0:1-5.

12. Medina-Tapia A, Molina-Sócola FE, Llerena-Manzorro L, López-Herrero F, Castilla-Martino M, Martínez-Borrego A, et al. Congenital retinal macrovessel associated with retinal peripheral telangiectasia and retinal ischaemia. Arch Soc Esp Oftalmol. 2017;92:338-42.

13. Goel N, Kumar V, Ghosh B. Congenital retinal macrovessel associated with vitreous hemorrhage. J AAPOS. 2017;21:83-5.

14. Arai J, Kasuga Y, Koketsu M, Yoshimura N. Development and spontaneous resolution of serous retinal detachment in a patient with a congenital retinal macrovessel. Retina. 2000;20:674-6.

15. Pichi Francesco K, Freund B, Ciardella A, Morara M, Abboud EB, Ghazi N, et al. Congenital retinal macrovessel and the association of retinal venous malformations with venous malformations of the brain. JAMA Ophthalmol. 2018;136(4):372-9.

16. Archer DB, Deutman A, Ernest JT, Krill AE. Arteriovenous communications of the retina. Am J Ophthalmol. 1973;75:224-41.

17. Shahlaee A, Pefkianaki M, Hsu J, Ho AC. Measurement of foveal avascular zone dimensions and its reliability in healthy eyes using optical coherence tomography angiography. Am J Ophthalmol. 2016;161:50-5.

18. Guo J, She X, Liu X, Sun X. Repeatability and reproducibility of Foveal avascular zone area measurements using AngioPlex spectral domain optical coherence tomography angiography in healthy subjects. Ophthalmologica. 2017;237:21-8.

19. Venugopal JP, Rao HL, Weinreb RN, Pradhan ZS, Dasari S, Riyazuddin M, et al. Repeatability of vessel density measurements of optical coherence tomography angiography in normal and glaucoma eyes. Br J Ophthalmol. 2018;102:352-7.

\section{Publisher's Note}

Springer Nature remains neutral with regard to jurisdictional claims in published maps and institutional affiliations.

\section{Ready to submit your research? Choose BMC and benefit from:}

- fast, convenient online submission

- thorough peer review by experienced researchers in your field

- rapid publication on acceptance

- support for research data, including large and complex data types

- gold Open Access which fosters wider collaboration and increased citations

- maximum visibility for your research: over $100 \mathrm{M}$ website views per year

At BMC, research is always in progress.

Learn more biomedcentral.com/submissions 